\title{
TORÇÃO DO GRANDE OMENTO
}

\section{TORSION OF GREATER OMENTUM}

\section{Leonardo Fernandes Valentim, AsCBC-RJ ${ }^{1}$; Luiz Fernando Nunes, AsCBC-RJ ${ }^{2}$ Zenilde Fernandes Mendes,TCBC-RJ ${ }^{3}$}

\section{INTRODUÇÃO}

Condição rara, primeiramente descrita em 1899 por Eitel $^{1}$, a torção do grande omento se apresenta como abdome agudo de difícil diagnóstico etiológico pré-operatório, guardando a elucidação, geralmente, para a laparotomia.

Apresentamos dois casos operados no Serviço de Cirurgia Geral do Hospital Cardoso Fontes nos últimos dez anos.

\section{RELATO DOS CASOS}

Caso 1 - Homem de 37 anos, exibia dor em fossa ilíaca direita há três dias, com náuseas, anorexia e febre não aferida. Ao exame físico: abdome com descompressão dolorosa e massa palpável na fossa ilíaca direita. O leucograma evidenciou 10700 células e seis bastões. Com hipótese diagnóstica de apendicite aguda, foi submetido à laparotomia (incisão de Jalaguier) que evidenciou torção com necrose parcial do grande omento, achando-se os demais órgãos normais. Foram realizadas omentectomia parcial e apendicectomia. Evoluiu sem intercorrências no pós-operatório.

Caso 2 - Homem de 26 anos apresentava dor abdominal há 48 horas, acompanhada por anorexia, febre de $37,8^{\circ} \mathrm{C}$, sem náuseas ou vômitos. Ao exame físico: defesa abdominal e descompressão dolorosa em quadrante inferior direito, e hérnia inguinal direita, redutível, não dolorosa. A leucometria revelou 16400 células e a rotina radiológica foi inespecífica. $\mathrm{Na}$ laparotomia, encontrou-se apenas torção epiplóica no sentido horário, com necrose de sua porção distal, (Figuras 1 e 2). $\mathrm{O}$ apêndice e demais órgãos eram normais. Evoluiu sem intercorrências no pós-operatório.

\section{DISCUSSÃO}

A torção do grande omento representa desafio diagnóstico pré-operatório no abdome agudo (apenas 0,6 a 4,8\% de todos os casos). É descoberta, na maioria das vezes, durante a laparotomia ${ }^{2}$. Acomete qualquer idade, com predominância nas $4^{\mathrm{a}}$ e $5^{\mathrm{a}}$ décadas. Pode ser primária, na ausência de processos intra-abdominais associados, como descrito no caso $1 \mathrm{ou}$, mais freqüentemente, secundária, quando relacionada a hérnias (condição mais comum, conforme presente no caso 2), cistos, tumores, ou outras doenças intra-abdominais.

A torção primária tem como fatores predisponentes as malformações anatômicas, como o epíploon bífido, projeções lingulares do órgão, alterações na distribuição de sua gordura (principalmente em obesos), e anomalias constitucionais em seu suprimento sanguíneo ou na formação de seu
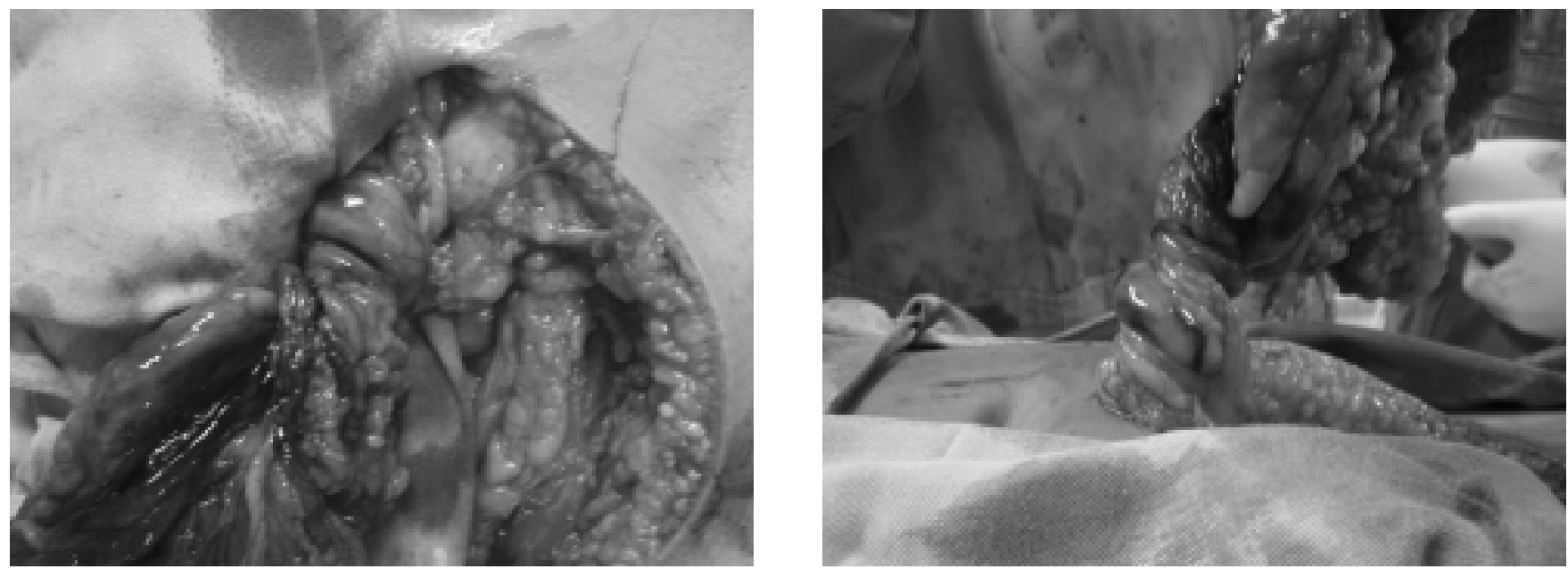

Figuras 1 e 2 - É demonstrada a torção do grande epíplon no sentido horário, com isquemia em sua porção distal.

1. Ex- Residente do Serviço de Cirurgia Geral do Hospital Cardoso Fontes -RJ

2. Cirurgião da Emergência do Hospital Cardoso Fontes -RJ;

3. Cirurgiã do Serviço de Cirurgia Geral do Hospital Cardoso Fontes- RJ; Mestre em Cirurgia Gastroenterológica pela Universidade Federal Fluminense.

Recebido em: 14/09/2005

Aceito para publicação em: 04/01/2005

Trabalho realizado no Serviço de Cirurgia Geral do Hospital Cardoso Fontes- RJ. 
pedículo. São fatores precipitantes do movimento de torção: o trauma local, peristalse aumentada por alimentação vigorosa, e aumento da pressão intra-abdominal, por exercícios físicos intensos, tosse ou espirro ${ }^{3}$.

Frente à conjunção de fatores predisponentes e de precipitantes, ou na presença de doenças intra-abdominais que sirvam como ponto de fixação para a torção, ocorre inicialmente o comprometimento do retorno venoso. O segmento distal torna-se congesto e edemaciado o que resulta em extravasamento hemorrágico, espelhado pelo fluido sero-sanguinolento na cavidade peritoneal. Se o processo permanece, ocorre oclusão arterial, com infarto hemorrágico e necrose adiposa.

Este quadro é manifesto através de dor abdominal, mais frequiente à direita, devido ao maior tamanho e mobilidade que o omento exibe deste lado. Febre baixa pode ser acompanhada por náuseas, vômitos e anorexia. O exame físico costuma demonstrar dor, defesa parietal no quadrante inferior direito e massa palpável, presente em apenas $33 \%$ dos casos. $\mathrm{O}$ hemograma pode revelar discreta leucocitose. $\mathrm{O}$ diagnóstico diferencial se faz com apendicite aguda, colecistite aguda, torção de ovário e outras doenças anexiais, diverticulite aguda, hematoma do músculo reto abdominal e infarto segmentar idiopático de epíploon.

Dentre os exames de imagens, a ultra-sonografia pode revelar massa aderida ao peritônio. A tomografia computadorizada apresenta maior acurácia, eventualmente evidenciando distribuição concêntrica de gordura que converge radialmente para a lesão. À ressonância magnética podese identificar imagem hiperintensa (gordura) circundando estrutura vertical hipointensa (epíplon) ${ }^{4}$.

O tratamento cirúrgico consiste na ressecção do segmento afetado (omentectomia), realizada por via laparoscópica, preferencialmente, ou por laparotomia. Alguns autores acreditam tratar-se de doença autolimitada, com bons resultados com tratamento conservador à base de dieta oral zero, analgesia e repouso, quando for obtido o difícil diagnóstico pré-operatório. Quando de diagnóstico intra-operatório, a ressecção da porção com necrose, para diminuir as aderências que podem vir a se formar, é a regra. ${ }^{5}$

\begin{abstract}
We present two cases of greater omental torsion, a rare condition of acute abdominal pain, emphasizing the clinical manifestations and imaging findings, which can lead us to the difficult preoperative diagnosis of this entity (Rev. Col. Bras. Cir. 2005; 32(5): 287-288).
\end{abstract}

Key words: Omentum; Torsion; Abdominal pain; Diagnostic imaging.

\section{REFERÊNCIAS}

1. Özbey H, Salman T, Celik A. Primary torsion of the omentum in a 6-year-old boy: report of a case. Surg Today. 1999; 29(6):568-9.

2. Saber AA, LaRaja RD. Omental torsion. eMed [serial on the Internet]. 2002 [cited 2005 July 18];19(3):[about 12 p.]; Available from: http://www.emedicine.com/med/topic2731.htm

3. Karayiannakis AJ, Polychronidis A, Chatzigianni E, et al. Primary torsion of the greater omentum: report of a case. Surg Today. 2002; 32(10):913-5.

4. Maeda T, Mori H, Cyujo M. CT and MR findings of torsion of greater omentum: a case report. Abdom Imaging. 1997; 22(1):45-6.
5. Miguel Perelló J, Aguayo Albasini JL, Soria Aledo V. Torsión de epiplón: las técnicas de imagen pueden evitar intervenciones innecesarias. Gastroenterol Hepatol. 2002; 25(8):493-6.

Endereço para correspondência:

Leonardo Fernandes Valentim

Av. Geremário Dantas, 269, apto. 402

Jacarepaguá

22735-000 - Rio de Janeiro - RJ 